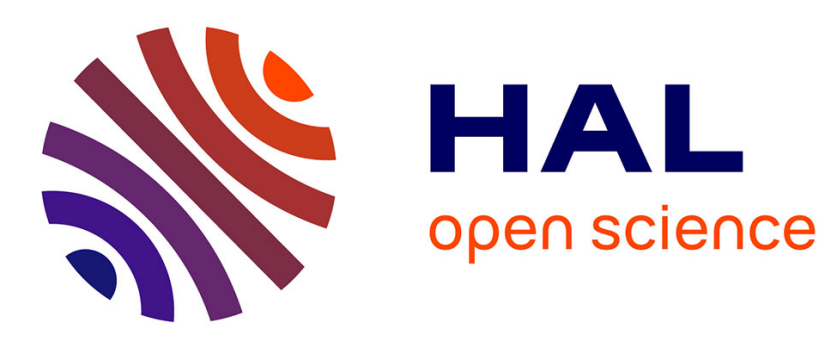

\title{
Evaluation of printed-circuit boards materials for high temperature operation
}

\author{
Oriol Aviño Salvado, Wissam Sabbah, Cyril Buttay, Hervé Morel, Pascal \\ Bevilacqua
}

\section{- To cite this version:}

Oriol Aviño Salvado, Wissam Sabbah, Cyril Buttay, Hervé Morel, Pascal Bevilacqua. Evaluation of printed-circuit boards materials for high temperature operation. HiTEN, IMAPS, Jul 2017, Cambridge, United Kingdom. hal-01565131

\section{HAL Id: hal-01565131 \\ https://hal.science/hal-01565131}

Submitted on 19 Jul 2017

HAL is a multi-disciplinary open access archive for the deposit and dissemination of scientific research documents, whether they are published or not. The documents may come from teaching and research institutions in France or abroad, or from public or private research centers.
L'archive ouverte pluridisciplinaire HAL, est destinée au dépôt et à la diffusion de documents scientifiques de niveau recherche, publiés ou non, émanant des établissements d'enseignement et de recherche français ou étrangers, des laboratoires publics ou privés. 


\title{
Evaluation of printed-circuit boards materials for high temperature operation
}

\author{
Oriol Aviño-S alvado, Wissam S abBah, Cyril Buttay, Hervé Morel, Pascal Bevilacqua \\ Université de Lyon, F-69621, France \\ CNRS, UMR5005, France, \\ INSA Lyon, \\ Laboratoire Ampère, \\ bâtiment L. de Vinci, 21 avenue Capelle \\ F-69621, France \\ cyril.buttay@insa-lyon.fr
}

\begin{abstract}
This article presents the long term $(1000 \mathrm{~h})$ behaviour of two printed-circuit board materials (Panasonic R1755V, a high- $\mathrm{T}_{\mathrm{G}}$ glass-epoxy composite and Arlon $85 \mathrm{~N}$, a polyimide-based laminate) stored at high temperature $\left(190^{\circ} \mathrm{C}\right)$. Tests are performed in air and in nitrogen atmospheres. Electrical and physical measurements are performed regularly (once per week).

Almost no degradation is observed for both materials, when stored in nitrogen. On the contrary, the board stored in air show the consequences of ageing. This is especially true for the glass-epoxy material, which becomes unusable after 2 weeks, because of large swelling.
\end{abstract}

\section{Keywords}

PCB; ageing; polyimide; FR4; oxygen

\section{Introduction}

Many applications require electronics systems which can operate in relatively high temperatures. For example, in the oil and gas industry, circuits are required to operate in ambient temperatures of $150{ }^{\circ} \mathrm{C}, 200{ }^{\circ} \mathrm{C}$, or more [1]. Depending on their location on the car, automotive electronics can experience ambient temperatures of more than $175^{\circ} \mathrm{C}[2]$.

Organic substrates such as epoxy-based Printed Circuit Boards (PCBs) are attractive because of their low cost (a few $€$ per $\mathrm{dm}^{2}$ ), process availability (can be sourced from many companies), and because they offer a high density of interconnections (50 $\mu \mathrm{m}$ track-width and thinner). This is especially true for the automotive market, where ceramic substrates are often considered too expensive.

High temperature operation is also a key capability for some power electronic systems [3], as they operate in harsh conditions, or because they dissipate a lot of heat (hundreds of $\mathrm{W} / \mathrm{cm}^{2}$ ). Many power electronic chips (diodes and transistors, either made out of silicon or silicon carbide) are rated for a maximum junction temperature of $175^{\circ} \mathrm{C}$. While they are usually mounted on high performance ceramic substrates, not on organic PCBs, these chips require a number of peripheral circuits to be mounted in close vicinity [4]. For example, power MOSFET transistors require some gate drive Integrated Circuits (ICs) to operate. Such ICs can operate at the same junction temperature as the transistors they drive, if not higher [5]. However, these peripheral circuits do not carry as much current nor do they dissipate as much power as the power chips. Therefore, they do not require mounting on ceramic substrates, and can be mounted on high temperature-capable PCBs instead.

Shaddock et al. [6] investigated the behaviour of several PCB materials at temperatures ranging from 200 to $250{ }^{\circ} \mathrm{C}$, over large periods of time (up to $10000 \mathrm{~h}$ ). It was found that protecting the boards from oxygen was important to increase lifetime. This was confirmed by Lahokallio et al. [7] who found that PCBs (FR4 and hydrocarbon-ceramic laminate) tested from $200{ }^{\circ} \mathrm{C}$ to $240{ }^{\circ} \mathrm{C}$ suffered strongly from oxidation.

In this paper, we investigate the ageing behaviour of a more standard material (a high- $\mathrm{T}_{\mathrm{G}}$ FR4) and compare it to a polyimide-based laminate. The experimental protocol is detailed in the next section. A preliminary experiment, presented in section 3 , is run to define the test conditions. The results of the tests are presented in section 4 and discussed in section 5 .

\section{Experimental Protocol}

\subsection{Test Vehicles}

Two materials were tested: a FR4-type material (Panasonic R1755-V, with a $T_{g}>170{ }^{\circ} \mathrm{C}$ ) and a polyimidetype (Arlon $85 \mathrm{~N}, T_{g}>250{ }^{\circ} \mathrm{C}$ ). Both materials were 


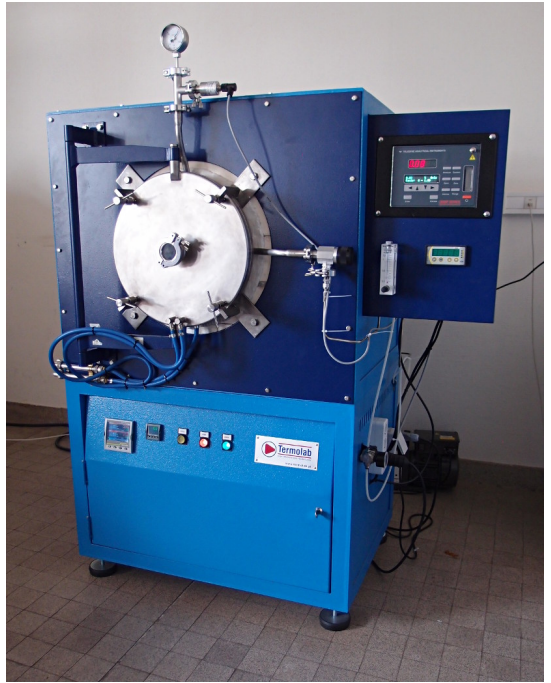

Figure 1: Chamber used for isothermal ageing at low oxygen percentage $(<0.1 \%)$, using an oxygen monitor and a low flow of nitrogen ( 0.1 standard litre per minute).

used in the form of 6-layer patterned boards (Processed by Elvia, France), with $70 \mu \mathrm{m}$ Copper, and $1.6 \mathrm{~mm}$ total thickness. Pad finish is Ni/Au $(6 \mu \mathrm{m} / 80 \mathrm{~nm})$. The test vehicles received a solder resist layer on both sides (XV501T, Imagesecure).

The test boards contain 3 groups of features:

- a surface isolation resistance (SIR) pattern, which is an interdigitated pattern with a $500 \mu \mathrm{m}$ distance between fingers, and $580 \mathrm{~mm}$ total finger length. This pattern is biased during the ageing test to produce an electrical field of $25 \mathrm{~V} / \mathrm{mm}$ [8].

- 32 daisy-chained vias (hole diameter $450 \mu \mathrm{m}$ );

- 2 planar capacitors (electrodes size $20 \times 20 \mathrm{~mm}^{2}$ ) to detect any change in thickness of the PCB

For some of the test described below, some test vehicles were separated in small coupons $\left(\approx 2 \times 2 \mathrm{~cm}^{2}\right.$ using shears. No damage (e.g. delamination of the edges of the coupons) was observed after this operation.

\subsection{Accelerated ageing}

After a preliminary drying $\left(6 \mathrm{~h}\right.$ at $\left.120{ }^{\circ} \mathrm{C}[9,10]\right)$, the test vehicles are placed in an oven for isothermal ageing (storage test). Two test conditions are evaluated in this paper: ageing in air, using a standard forced-convection oven (MMM Venticell), or in nitrogen with the system presented in Fig. 1 (Termolab). This chamber was especially designed for long term testing: it is gas-tight, requiring only a small flow of nitrogen (0.1 SLM) to prevent oxygen to enter. An oxygen monitor is connected to the exhaust of the chamber to ensure the oxygen concentration remains below $0.1 \%$, and to inject more nitrogen if required.

The ageing tests are run for $1008 \mathrm{~h}$ (6 weeks).
In the ovens, the boards are maintained by edgeboard connectors rated at $200{ }^{\circ} \mathrm{C}$ (Vishay EB45P0K2030X). These connectors are used to bias the SIR patterns of the boards. Alpha Wire PTFE-insulated wires enter the ovens and are soldered (HMP alloy) to the connectors. The reliability of this setup is satisfying, as no failure was observed throughout the tests.

The test temperature was defined by preliminary tests ("step stress tests") which are presented in section 3.

\subsection{Characterisation}

Before the beginning of the ageing test, and then periodically (every week, which corresponds to $168 \mathrm{~h}$ ), the samples are submitted to the following characterisations:

- weighting (Ohaus Adventurer Pro 210, 1 mg resolution). For the first measurement, the samples are dried beforehand.

- photography with a Leica M205 binocular, equipped with a camera and a save/recall system which allows to use identical settings (lightning, white balance, etc.). This produces consistent images throughout the duration of the ageing tests.

- electrical measurements: The capacitance pattern is measured using an Agilent E4990 impedance analyser. A Keithley 2410 source and measure unit (SMU) is used to measure both the resistance of the vias daisy chain (with a 4-point connection) and the surface isolation resistance pattern. This equipment can indeed measure resistances ranging from $100 \mu \Omega$ up to $200 \mathrm{M} \Omega$.

- Finally, micro-sections are performed on some test coupons using the following protocol: encapsulation in acrylic resin (Buehler Varikleer); cutting with a low speed diamond saw; grinding with P1200 paper (60 s); polishing on clothes with $6 \mu \mathrm{m}, 3 \mu \mathrm{m}$ and $1 \mu \mathrm{m}$ diamond particles $(180,180$ and $120 \mathrm{~s}$ respectively). Final polishing is performed with $50 \mathrm{~nm}$ colloidal silica (60 s), and the sample is rinsed and dried.

\section{Definition of the Test Conditions}

A preliminary experiment was run in order to define the temperature to be used for the ageing tests: In this experiments, 6 coupons of FR4 and polyimide boards are placed in each of the ovens (air and nitrogen atmospheres). Starting at $150{ }^{\circ} \mathrm{C}$ (arbitrary value), the temperature is then increased by $20^{\circ} \mathrm{C}$ every $24 \mathrm{~h}$. For each step, a coupon is removed from the oven and weighted.

The results are presented in Fig. 2. No weight loss is observed on the samples up to $210^{\circ} \mathrm{C}$. After $24 \mathrm{~h}$ at $230{ }^{\circ} \mathrm{C}$, the FR4 coupon stored in air shows a dramatic weight loss (almost $8 \%$ ). After $24 \mathrm{~h}$ at $250{ }^{\circ} \mathrm{C}$, the FR4 


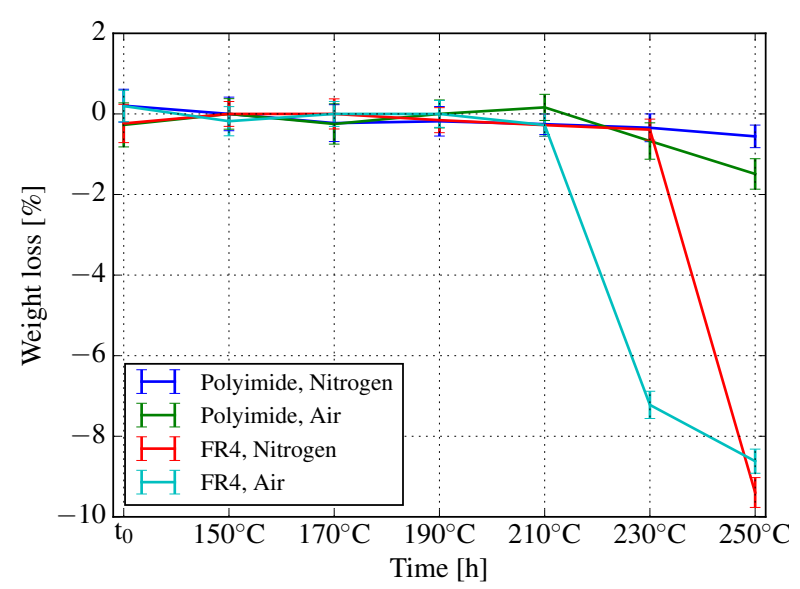

Figure 2: Weight loss measured on PCB coupons during stepstress testing (the test temperature is increased every $24 \mathrm{~h}$, one coupon is removed from the test chamber after each step to be characterised).

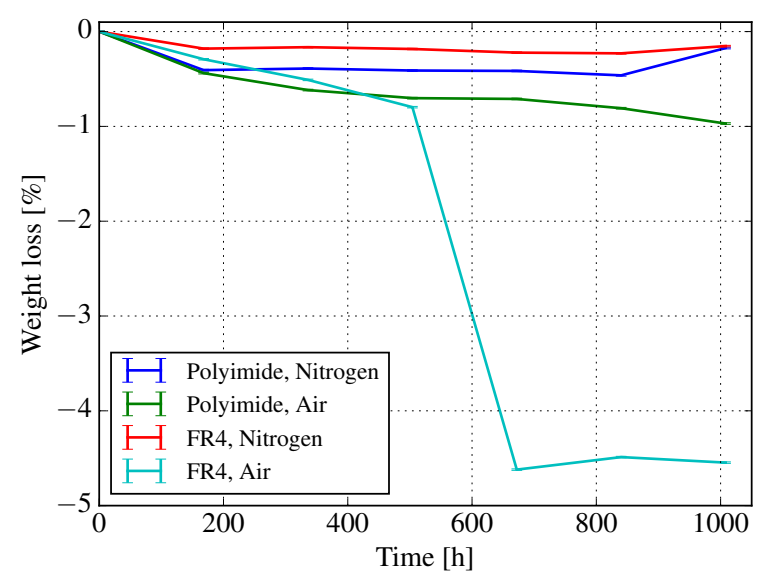

Figure 3: Weight loss during isothermal ageing at $190{ }^{\circ} \mathrm{C}$, for polyimide and FR4 boards, tested in air and nitrogen. Error bars are placed on the graph as in Fig. 2, but they are barely visible because the boards tested here are much heavier than the coupons used in section 3, resulting in a much more accurate measurement with a $1 \mathrm{mg}$ resolution scale.

coupon stored in nitrogen also exhibits a comparable weight loss. Regarding the polyimide coupons, a nonnegligible (although much lower than for FR4) weight loss is observed for the coupon stored in air (1.5\%).

As a consequence, a $190{ }^{\circ} \mathrm{C}$ test temperature was chosen for the isothermal tests.

\section{Test Results}

The weight loss measurements observed during ageing are presented in Fig. 3. They show a small weight loss after the first week (168 h) for all boards. This weight loss tends to be larger for polyimide boards. Then, the weight tends to stabilise until $500 \mathrm{~h}$. At that point, the FR4 board stored in air shows a strong weight loss $(4.5 \%)$. No further change is observed for the remain-

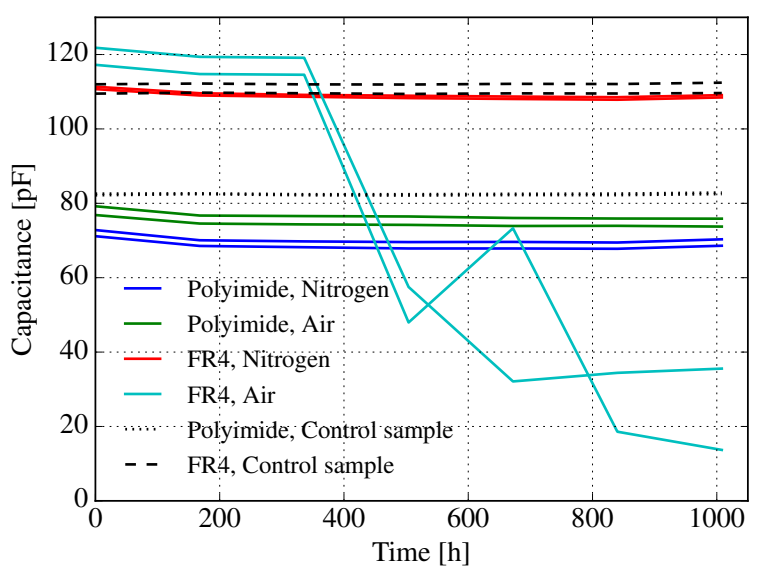

Figure 4: Capacitance change during isothermal ageing at $190{ }^{\circ} \mathrm{C}$, for polyimide and FR4 boards, tested in air and nitrogen.

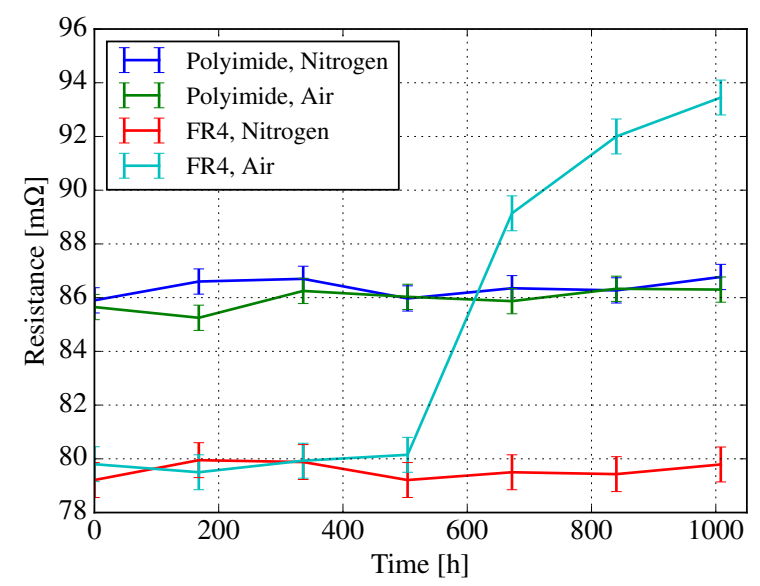

Figure 5: Resistance change (vias daisy-chain) during isothermal ageing at $190{ }^{\circ} \mathrm{C}$, for polyimide and FR4 boards, tested in air and nitrogen.

ing $500 \mathrm{~h}$. A small increase in weight is observed for the polyimide board stored in nitrogen at the end of the test, and is unexplained (unfortunately, for this measurement, we did not use a control sample, so a measurement error cannot be ruled-out).

Regarding the change in capacitance (Fig. 4), the results are comparable, with almost no evolution for the polyimide boards, as well as for the FR4 board stored in nitrogen (two capacitor patterns are monitored per board, producing two curves in Fig. 4). The small changes, especially for the first $168 \mathrm{~h}$, are correlated with the weight loss.

For the FR4 board stored in air, however, the capacitance drop is much larger and starts one week sooner than the corresponding weight loss (Fig. 3). The large capacitance drop $(\approx 80 \%)$ is related to a noticeable swelling of the board, with large blisters forming (the apparent thickness of the board is more than doubled in some places). Larger blisters tend to concentrate in the capacitance pattern, probably because of the gas-tight area formed by the copper electrodes of the capacitor. 


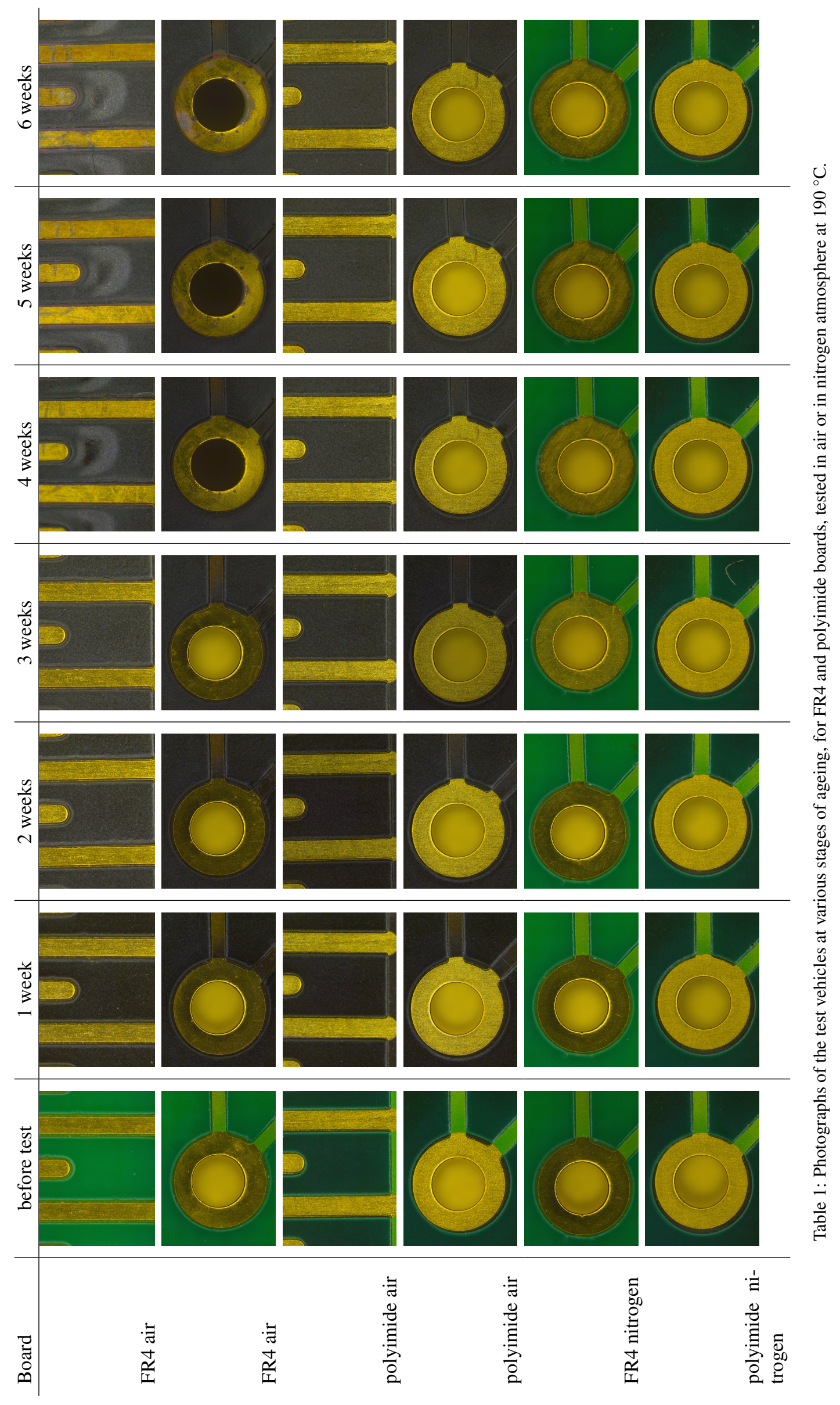




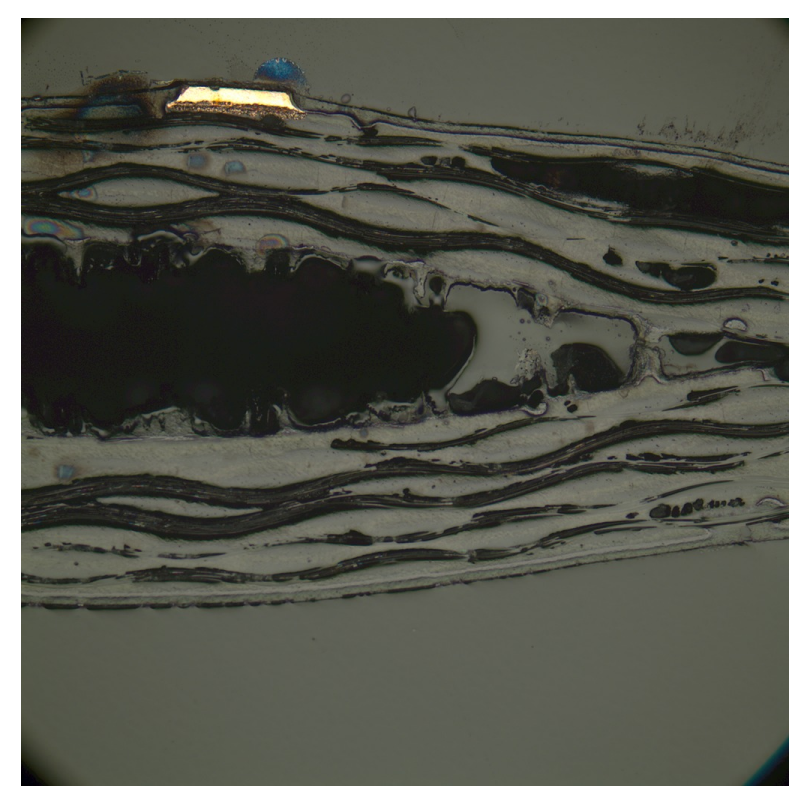

Figure 6: Cross-section of a FR4 coupon after 5 weeks ( $840 \mathrm{~h}$ ) at $190{ }^{\circ} \mathrm{C}$ in air, showing the swelling of the board.

The resistance of the vias is presented in Fig. 5. Again, the evolution is correlated with the change in weight (Fig. 3). The polyimide boards and the FR4 board stored in nitrogen show no noticeable change, while the FR4 board stored in air exhibits a strong increase $(15 \%)$. As with the capacitances, this can be related to the swelling of the board. However, contrary to the capacitances (Fig. 4), the change in resistance occurs between the $3^{\text {rd }}$ and the $4^{\text {th }}$ week (504 to $672 \mathrm{~h}$ ), not between the $2^{\text {nd }}$ and the $3^{\text {rd }}$ ( 376 to $504 \mathrm{~h}$ ). Overall, no rupture of the vias was observed.

The surface isolation resistance (SIR) was found to exceed the capability of our testing equipment (200 M $\Omega$ ) for the FR4 and polyimide boards in air and in nitrogen atmospheres. Only the FR4 board tested in air showed a drop in SIR after 4 weeks (1.32 M $\Omega$, and $600 \mathrm{k} \Omega$ after 5 weeks). The test could non be extended to the $6^{\text {th }}$ week, as the swelling of the board prevented its insertion in the edgeboard connectors (used for the voltage bias in the oven).

Finally, some of the images of the boards, taken during the course of the ageing tests, are presented in Tab. 1. Many areas of the boards were photographed, and they all show the same evolution: for the boards tested in air, there is a colour change after the first week of test, while the boards tested in nitrogen do not show any colour change over the duration of the tests. Another change is visible for the FR4 board tested in air, after 4 weeks: the PCB material is no longer uniform in colour, and shows some lighter patches. This is correlated with some corrosion of the Ni/Au plated areas (especially visible after 5 weeks on the via - second line in Tab 1). For the other cases (polyimide boards and FR4 board tested in nitrogen), no such change is visible on the metal areas.

\section{Discussion}

Besides the board material, the test atmosphere has a strong influence on the ageing behaviour: the boards tested in nitrogen show no swelling, no discolouration, and almost no change in weight. On the contrary, despite its high $\mathrm{T}_{\mathrm{G}}$, the polyimide board tested in air exhibits a non-negligible weight loss $(1 \%)$ over the duration of the tests. This confirms the effect of oxygen observed in [6] and [7].

The fast degradation of the FR4 material in air could be expected, as the tests were performed at $190{ }^{\circ} \mathrm{C}$, higher than the $\mathrm{T}_{\mathrm{G}}$ of the material $\left(170^{\circ} \mathrm{C}\right)$. This degradation was detected through all the measurements, but at different times: weight loss (drop after 504 h); capacitance change (drop after $336 \mathrm{~h}$ ); via resistance (increase after 504 h); SIR (drop after 672 h); visual observation (after $672 \mathrm{~h}$ or 4 weeks). Basically, the capacitance measurement was the most sensitive measurement. A possible reason is that the large copper electrodes prevented the decomposition gases to permeate, resulting in an accelerated swelling. This swelling then propagated over the entire board. Eventually, this made it impossible to mount the board in the edgeboard connector. A cross section of a FR4 coupon tested in air is visible in Fig. 6, and shows the extend of the swelling.

The FR4 board tested in nitrogen did not show any noticeable ageing, despite it being stored at $190{ }^{\circ} \mathrm{C}$ (i.e. above its $\mathrm{T}_{\mathrm{G}}$ ) for more than $1000 \mathrm{~h}$. Although operating over the glass transition temperature is not recommended because of the reduced mechanical strength of the board and because of its increased coefficient of thermal expansion, this might constitute a "low cost" high temperature prototyping platform: using a standard high- $\mathrm{T}_{\mathrm{G}}$ FR4 board instead of a more expensive material. To protect the board from the effect of the oxygen, a dedicated test chamber could then be used. Another solution, as proposed in [6], could be to use a protection layer such as high temperature parylene.

Regarding the polyimide boards, the effect of oxygen could be observed (darkening of the solder resist layer, non-negligible weight loss), but none of these effects translated in changes in electrical performance.

Finally, the Ni/Au finish of the copper tracks was found to have a satisfying stability, with no changes in aspect over the duration of the tests, whether in air or in nitrogen. The only changes were observed for the FR4 board tested in air, and are probably due to corrosion by the decomposition products of the board.

\section{Conclusion}

The high temperature $\left(190{ }^{\circ} \mathrm{C}\right)$, isothermal ageing of printed circuit board materials is presented in this article. Two materials are investigated, a high- $\mathrm{T}_{\mathrm{G}} \mathrm{FR} 4$ and a polyimide. While polyimide is preferable when operating in air, it is found that FR4 can nonetheless be used 
over long periods of time $(1000 \mathrm{~h})$, providing the tests are performed in a neutral atmosphere (nitrogen).

Several measurements were performed throughout the ageing tests to monitor the condition of the boards. It is found that the capacitance measurements are the most sensitive, as they were the first to detect the degradation of the FR4 board tested in air. Overall, the degradation could be detected through all the measurements (electrical parameters, weight, or visual inspection), albeit one to two weeks later.

As it allows the use of standard PCB materials, operating in nitrogen atmosphere could be an interesting solution for lab experiments and prototyping. An oxygen barrier, such as parylene, could possibly provide the same kind of protection for the final applications.

\section{Acknowledgements}

This work was funded part of the GENOMEPREMICES initiative.

\section{References}

[1] R. Beckwith, "Downhole Electronic Components: Achieving Performance Reliability," JPT, pp. 42-53, Aug. 2013.

[2] J. G. Kassakian and D. J. Perreault, "The Future of Electronics in Automobiles," in Proceedings of the International Symposium on Power Semiconductor Devices and ICs (ISPSD), Osaka, Japan, 2001, pp. 15-19.

[3] C. Buttay, D. Planson, B. Allard, D. Bergogne, P. Bevilacqua, C. Joubert, M. Lazar, C. Martin, H. Morel, D. Tournier, and C. Raynaud, "State of the art of high temperature power electronics," Materials Science and Engineering: B, vol. 176, no. 4, pp. 283-288, 2011, microtechnology and Thermal Problems in Electronics. [Online]. Available: http://www.sciencedirect. com/science/article/pii/S0921510710006136

[4] C. Buttay, K. El Falahi, R. Robutel, S. Hascoët, C. Martin, B. Allard, and C. Johnson, Mark, "Integrated packaging allows for improvement in switching characteristics of silicon carbide devices," in Power Control Intelligent Motion 2014 (PCIM 2014), Nuremberg, Germany, May 2014, p. 8 p., 8 pages. [Online]. Available: https://hal.archives-ouvertes.fr/hal-00997355

[5] K. El Falahi, B. Allard, D. Tournier, and D. Bergogne, "Evaluation of commercial SOI Driver performances While Operated in Extreme Conditions (up to 200C)," in Proceedings of the High Temperature Electronics Conference (HiTEC). Albuquerque, NM: IMAPS, May 2010.

[6] D. Shaddock and L. Yin, "Reliability of high temperature laminates," in International Conference and Exhibition on High Temperature Electronics Network (HiTEN). International Microelectronics Assembly and Packaging Society, 2015.

[7] S. Lahokallio, M. Hoikkanen, J. Vuorinen, and L. Frisk, "High-temperature storage testing of acf attached sen- sor structures," Materials, vol. 8, no. 12, pp. 8641-8660, 2015.

[8] IPC, "Ipc-tm-650 test methods manual - 2.6.3.7 surface isolation resistance," IPC, Tech. Rep., 2007.

[9] — , "Ipc-1601a - printed board handling and storage guidelines," 2016.

[10] I. Charrier, Y. Jouffrey, C. Villette, and B. Dunn, "Moisture pick-up and minimum drying conditions of epoxy and polyimide-glass printed circuit board," 2005. [Online]. Available: http://wiki.fed.de/images/8/ 88/Institut_de_soudure.pdf 